\title{
PENGARUH BUDAYA ORGANISASI, GAYA KEPEMIMPINAN DAN PENGAWAS TERHADAP MOTIVASI SERTA DAMPAKNYA TERHADAP KINERJA PEGAWAI DINAS PEKERJAAN UMUM (PU) KABUPATEN BATANG HARI JAMBI
}

\author{
${ }^{1}$ Muhammad Oceano Fauzan, ${ }^{2}$ Fathiyah \\ ${ }^{1}$ Mahasiswa Magister Manajemen Fakultas Ekonomi Universitas Batanghari, \\ ${ }^{2}$ Dosen Fakultas Ekonomi Universitas Batanghari
}

\begin{abstract}
An organization was formed not only intended to produce the product. The resulting products of an organization can be a goods and service also can distinguish thoseorganizations with other organizations. While the perpetrators who carry out the work referred to the performance. The notion of performance in General can be said asthe magnitude of the contributions or the results of the work accomplished provided employees towards progress and development or organizational goals or organisation where he worked. This type of research is descriptive research and verifikatif with analysis tools in the form of path analysis (Path analysis). This research was conducted in the public works agency Batang Hari Jambi with a number of employees as many as 95 people as research samples. the results of hypothesis testing simultaneously between the variables $(X 1)$, organization culture, leadership style (X 2), supervision (X 3), with a motivational variable (Y) shows that $F$ calculate the significant level 9,669 0000. from the table above shows that the value of $t$ count variable (Y) motivation is significant level 4,488 0000. because 0.000 $\mathrm{HO}$ is rejected then the $0.05<$ Hoaccepted (significant). The results show that partially motivated $(Y)$ effect on performance $(Z)$ on public works Districts Batanghari Jambi.
\end{abstract}

Keywords: organizational culture, leadership style

\section{PENDAHULUAN}

Pentingnya kualitas sumber daya manusia karena peranannya sebagai motor penggerak yang dapat mempengaruhi kemampuan dan keberhasilan pencapaian tujuan organisasi secara efektif dan efisien. Pengembangan sumber daya manusia merupakan suatu condition sine qua non, atau sesuatu yang tidak dapat dihindarkan yang harus terus dilakukan, karena bagaimanapun canggihnya sarana dan prasarana organisasi tanpa ditunjang oleh sumber daya manusia yang berkualitas, organisasi itu tidak dapat maju dan berkembang.

Pegawai merupakan sumber daya manusia yang penting bagi suatu organisasi, karena memiliki bakat atau kemampuan, tenaga dan kreatitas yang sangat dibutuhkan oleh organisasi untuk mencapai tujuan. Sebaliknya sumber daya manusia juga mempunyai berbagai macam kebutuhan yang ingin dipenuhi. Keinginan untuk memenuhi kebutuhan inilah yang dipandang sebagai pendorong atau penggerak bagi seseorang untuk melakukan sesuatu, termasuk untuk bekerja.

Dalam kondisi lingkungan kerja yang penuh dengan tekanan, pegawai diharapkan juga untuk memiliki komitmen yang besar terhadap organisasi dimana pegawai bekerja. Sebab dengan memiliki komitmen yang tinggi berarti pegawai secara konsisten akan mencapai kinerja yang optimal untuk memajukan organisasi.

Pengaruh Budaya Organisasi, Gaya Kepemimpinan dan Pengawas terhadap Motivasi Serta Dampaknya terhadap Kinerja Pegawai Dinas Pekerjaan Umum (PU) Kabupaten Batang Hari Jambi 
Budaya organisasi itu cenderung untuk diwujudkan oleh anggota organisasi, sehingga orang yang hidup dalam lingkungan tersebut merasa bisa hidup menjadi lebih baik. Ada delapan butir nilai-nilai primer yang seharusnya ada pada tiap-tiap organisasi yang jika diolah dengan baik dapat menjadi budaya organisasi yang positif, dan akan mengakibatkan loyalitas dan produktivitas. Delapan butir nilai-nilai budaya itu disebut sebagai asas-asas, yaitu : asas tujuan, asas konsensus, asas keunggulan, asas prestasi, asas kesatuan, asas empiris, asas keakrapan, dan asas integritas.

Berbicara tentang budaya organisasi, biasanya yang dimaksud ialah adanya persepsi yang sama dikalangan seluruh anggota organisasi tentang makna hakiki kehidupan bersama. Pengertian sederhana tersebut sesungguhnya berarti, bahwa dalam lingkungan suatu organisasi mutlak diperlukan pemahaman yang tepat tetang cara-cara bertindak dan berperilaku yang baik bagi organisasi. Implikasinya yang sangat mendasar adalah, bahwa kehadiran dan keberadaan seseorang sebagai anggota organisasi hanya akan diterima oleh berbagai pihak lain, seperti atasan langsung, manajemen, dan rekan-rekan setingkat apabila yang bersangkutan mampu, dan bersedia melakukan berbagai jenis penyesuaian dalam tindakan dan perilakunya sehingga mencerminkan penerimaannya tentang budaya organisasi.

Faktor kepemimpinan, dari atasan dapat memberikan pengayoman dan bimbingan kepada pegawai dalam menghadapi tugas dan lingkungan kerja yang baru. Pemimpin yang baik akan mampu menularkan optimisme dan pengetahuan yang dimilikinya agar pegawai yang menjadi bawahannya dapat melaksanakan pekerjaan dengan baik. Sehingga setiap pimpinan akan memperlihatkan gaya kepemimpinannya lewat ucapan, sikap tingkah lakunya yang dirasa oleh dirinya sendiri maupun orang lain. Sukses tidaknya pegawai dalam prestasi kerja dapat dipengaruhi gaya kepemimpinan atasannya.

Motivasi adalah dorongan, upaya dan keinginan yang ada didalam diri manusia yang mengaktifkan, memberi daya serta mengarahkan perilaku untuk melaksanakan tugas-tugas dengan baik dalam lingkup pekerjaannya (Hakim:2006). Robbins (2006) mendefinisikan motivasi sebagai proses yang ikut menentukan intensitas, arah, dan ketekunan individu dalam usaha mencapai sasaran. Motivasi sebagai proses yang bermula dari kekuatan dalam hal fisiologis dan psikologis atau kebutuhan yang mengakibatkan perilaku atau dorongan yang ditujukan pada sebuah tujuan atau insentif (Moekijat, 2001 dalam Hakim, 2006).

Suatu organisasi dibentuk tak lain hanya ditujukan untuk menghasilkan sesuatu produk. Produk yang dihasilkan suatu organisasi bisa berupa barang maupun jasa yang dapat membedakan organisasi tersebut dengan organisasi lain. Sedangkan pelaku yang melaksanakan pekerjaan disebut dengan kinerja. Pengertian kinerja secara umum dapat dikatakan sebagai besarnya kontribusi atau hasil kerja yang dicapai yang diberikan pegawai terhadap kemajuan dan perkembangan atau sasaransasaran organisasi atau organisasi dimana ia bekerja.

Sebagai seorang pemimpin, seharusnya dapat berbuat sesuatu yang berpengaruh kepada orang yang dipimpinnya, sehingga mereka melakukan pekerjaan dengan upaya lebih dari biasanya. Tugas dilakukan dengan lebih baik, pemeliharaan alat dan bahan dilakukan dengan lebih bertanggung jawab dan cermat. Inilah yang dinamakan dengan motivasi. Sebaliknya, orang yang bekerja berharap organisasi akan berbuat sesuatu bagi mereka yang dapat memenuhi kebutuhan mereka. Secara umum, dapat 
dikatakan bahwa semakin terpenuhi kebutuhan seseorang dalam suatu organisasi, semakin termotivasilah seseorang tersebut.

Ada beberapa faktor yang mempengaruhi keberhasilan pegawai dalam menjalankan tugas, faktor tersebut diantaranya adalah kemampuan pegawai dalam menjalankan tugasnya, kondisi budaya lingkungan organisasi, kepemimpinan dari top manajer dan lain-lain yang dapat memberikan rangsangan motivasi kepada pegawainya untuk berkinerja dengan baik.

\section{METODE PENELITIAN}

Jenis penelitian yang digunakan adalah penelitian deskriptif dan verifikatif dengan alat analisis berupa analisis jalur (Path analysis). Penelitian ini dilakukan di Dinas Pekerjaan Umum Kabupaten Batang Hari Jambi dengan jumlah pegawai sebanyak 95 orang sebagai sampel penelitian. Data dikumpulkan melalui 2 cara yaitu Library research dan Field research. Metode Library research menggunakan data seperti jurnal, tesis, makalah dan penelitian terkait yang berkaitan dengan budaya organisasi, gaya kepemimpinan, pengawasan, motivasi dan kinerja pegawai serta dengan mengumpulkan berbagai informasi yang berhubungan dengan objek penelitian yang diperoleh dari Dinas Pekerjaan Umum Kabupaten Batang Hari Jambi, sedangkan Field research menggunakan kuesioner dengan metode kuesioner tertutup yang sebelumnya telah diuji dengan uji validitas dan uji reliabilitas.

\section{DEFINISI OPERASIONAL}

Budaya Organisasi (X1). Menurut Peter F drucker dalam Tika (2006:4) budaya organisasi adalah pokok penyelesaian masalah-masalah ekternal dan internal yang pelaksanaannya dilakukan secara konsisten oleh suatu kelompok yang kemudian diwariskan kepada anggota-ang gota barusebagai cara yang tepat untuk, memahami, memikirkan dan merasakan teradap masalah-masalah terkait seperti diatas.

Gaya Kepemimpinan (X2). Menurut Yulk (pada Greenberg dan Baron 1993) mengatakan bahwa leadership kepemimpinan adalah merupak proses dimana seseorang individu mempengaruhi anggota group yang lainnya untuk mencapai tujuan organisasi.

Pengawasan (X3). Pengawasan dapat diartikan sebagai suatu proses untuk menetapkan pekerjaan apa yang sudah dilaksanakan, menilainya, dan bila perlu mengoreksi dengan maksud supaya pelaksanaan pekerjaan sesuai dengan rencana semula (Manullang,2002:128)

Motivasi $(Y)$. Kebutuhan manusia yang paling tertinggi, aktualisasi berbedabeda antara satu orang dengan yang lainnya. (A Maslow dalam Hasibuan 2005)

Kinerja (Z). Sedangkan menurut Robert L Mathis (2007;69) mengatakan: "banyaknya upaya yang dikeluarkan individu dalam mencurahkan tenaga sejumlah tertentu pada pekerjaan."

\section{HASIL DAN PEMBAHASAN}

Hasil

\section{Karakteristik responden.}

Dari total sampel 95 orang didapatkan bahwa responden berjenis kelamin lakilaki adalah sebanyak 64 (enam puluh empat) orang atau sebesar 67,37\% dan responden berjenis kelamin perempuan adalah sebanyak 31 (tiga puluh satu) orang 
atau sebesar 32,63\%. Hal ini mengindikasikan bahwa jumlah pegawai laki-laki lebih dominan dari pada pegawai perempuan (Tabel 1). Sedangkan berdasarkan tingkat pendidikan didapatkan berpendidikan S1 sebanyak 18 (delapan belas) orang atau sebesar 18,94\%, D3 sebanyak 3 (tiga) orang atau sebesar 3,16\%, SLTA sebanyak 73 (tujuh puluh tiga) orang atau sebanyak 76,84\%, dan SLTP 1 (satu) orang atau sebesar $1,06 \%$.

Tabel 1 Karakteristik responden berdasarkan jenis kelamin pada Dinas Pekerjaan Umum Kabupaten Batang Hari Jambi

\begin{tabular}{clccc}
\hline No & \multicolumn{1}{c}{ Jenis kelamin } & Frekuensi (Orang) & Persentase (\%) \\
\hline 1 & Laki-laki & & 64 & $67,37 \%$ \\
2 & Perempuan & & 31 & $32,63 \%$ \\
& & Total & 95 & $100,00 \%$ \\
\hline
\end{tabular}

Sumber data: Dinas Pekerjaan Umum Kabupaten Batang Hari jambi (2016)

Tabel 2 Karakteristik responden berdasarkan tingkat pendidikan pada Dinas Pekerjaan Umum Kabupaten Batang Hari Jambi

\begin{tabular}{clccc}
\hline No & & Pendidikan & Frekuensi & Persentase \\
\hline 1 & SLTP & & 1 & $1,06 \%$ \\
2 & SLTA & & 73 & $76,84 \%$ \\
3 & D3 & & 3 & $3,16 \%$ \\
4 & S1 & Total & 18 & $18,94 \%$ \\
& & 95 & $100 \%$ \\
\hline
\end{tabular}

Sumber data: Dinas Pekerjaan Umum Batang Hari Jambi (2016)

\section{Budaya Organisasi (X1).}

Atas dapat dikatakan bahwa Budaya Organisasi pada Dinas Pekerjaan Umum (PU) Kabupaten Batang Hari Jambi termasuk dalam katagori "Kuat" dengan total skor variabel Budaya Organisasi (X1) sebesar 3.422 dengan rentang skala 3230 3989, hal ini menunjukkan metode atau cara Budaya Organisasi yang digunakan, dapat meningkatkan kinerja pegawai pada Dinas Pekerjaan Umum (PU) Kabupaten Batang Hari Jambi dalam melaksanakan tugas sehari-hari.(tabel 3)

Tabel 3 Tanggapan responden mengenai budaya organisasi (X1)

\begin{tabular}{|c|c|c|c|c|c|c|c|c|c|c|c|c|c|c|}
\hline \multirow[t]{2}{*}{ No } & \multirow[t]{2}{*}{ Item } & \multicolumn{2}{|c|}{ SB } & \multicolumn{2}{|c|}{ B } & \multicolumn{2}{|c|}{ CB } & \multicolumn{2}{|c|}{ TB } & \multicolumn{2}{|c|}{ STB } & \multirow[t]{2}{*}{$\mathbf{n}$} & \multirow{2}{*}{$\begin{array}{l}\text { Skor } \\
\text { total }\end{array}$} & \multirow[t]{2}{*}{ Kategori } \\
\hline & & $\mathrm{Fi}$ & $\%$ & $\mathrm{Fi}$ & $\%$ & $\mathrm{Fi}$ & $\%$ & $\mathbf{F i}$ & $\%$ & $\mathbf{F i}$ & $\%$ & & & \\
\hline 1 & P1 & 21 & 35,59 & 23 & 38,98 & 12 & 20,34 & 2 & 3,39 & 1 & 1,70 & 95 & 380 & Setuju \\
\hline 2 & P2 & 5 & 8,48 & 30 & 50,84 & 21 & 35,59 & 1 & 1,70 & 2 & 3,39 & 95 & 349 & Setuju \\
\hline 3 & P3 & 0 & 0 & 21 & 35,59 & 36 & 61,02 & 2 & 3,39 & 0 & 0 & 95 & 326 & Setuju \\
\hline 4 & P4 & 0 & 0 & 27 & 45,77 & 30 & 50,84 & 2 & 3,39 & 0 & 0 & 95 & 325 & Setuju \\
\hline 5 & P5 & 14 & 23,73 & 24 & 40,67 & 19 & 32,20 & 1 & 1,70 & 1 & 1,70 & 95 & 361 & Setuju \\
\hline 6 & P6 & 0 & 0 & 30 & 50,84 & 27 & 45,76 & 1 & 1,70 & 1 & 1,70 & 95 & 323 & Setuju \\
\hline 7 & P7 & 0 & 0 & 37 & 62,71 & 19 & 32,20 & 2 & 3,39 & 1 & 1,70 & 95 & 337 & Setuju \\
\hline 8 & P8 & 0 & 0 & 30 & 50,84 & 25 & 42,38 & 2 & 3,39 & 2 & 3,39 & 95 & 345 & Setuju \\
\hline 9 & P9 & 11 & 18,64 & 22 & 37,29 & 23 & 38,98 & 2 & 3.39 & 1 & 1,70 & 95 & 436 & Setuju \\
\hline 10 & P10 & 1 & 1,70 & 29 & 49,15 & 27 & 45,76 & 2 & 3,39 & 0 & 0 & 95 & 330 & Setuju \\
\hline & & & & & & tal & & & & & & & 3422 & Kuat \\
\hline & & & & & & i-ra & & & & & & & 342,2 & Kuat \\
\hline
\end{tabular}

Sumber: data diolah (2016) 


\section{Gaya Kepemimpinan.}

Gaya kepemimpinan pada Dinas Pekerjaan Umum (PU) Kabupaten Batang Hari Jambi termasuk dalam katagori "Kuat" dengan total skor variabel Gaya kepemimpinan (X2) sebesar 5.951 dengan rentang skala 5.814 - 7.181 hal ini menunjukkan metode atau cara gaya kepemimpinan digunakan, dapat meningkatkan kinerja pegawai pada Dinas Pekerjaan Umum (PU) Kabupaten Batang Hari Jambi. (Tabel 4).

Tabel 4 Tanggapan responden mengenai Gaya Kepemimpinan (X2)

\begin{tabular}{|c|c|c|c|c|c|c|c|c|c|c|c|c|c|c|}
\hline \multirow[t]{2}{*}{ No } & \multirow[t]{2}{*}{ Item } & \multicolumn{2}{|c|}{ SB } & \multicolumn{2}{|r|}{ B } & \multicolumn{2}{|c|}{ CB } & \multicolumn{2}{|c|}{ TB } & \multicolumn{2}{|c|}{ STB } & \multirow[t]{2}{*}{$\mathbf{n}$} & \multirow{2}{*}{$\begin{array}{l}\text { Skor } \\
\text { total }\end{array}$} & \multirow[t]{2}{*}{ Kategori } \\
\hline & & $\mathbf{F i}$ & $\%$ & $\mathrm{Fi}$ & $\%$ & $\mathbf{F i}$ & $\%$ & $\mathbf{F i}$ & $\%$ & $\mathbf{F i}$ & $\%$ & & & \\
\hline 1 & P1 & 6 & 10,17 & 19 & 32,20 & 28 & 47,47 & 3 & 5,08 & 3 & 5,08 & 95 & 338 & Setuju \\
\hline 2 & P2 & 4 & 6,78 & 17 & 28,82 & 32 & 54,24 & 3 & 5,08 & 3 & 5,08 & 95 & 337 & Setuju \\
\hline 3 & P3 & 2 & 3,39 & 28 & 47,46 & 29 & 49,15 & 0 & 0 & 0 & 0 & 95 & 340 & Setuju \\
\hline 4 & P4 & 1 & 1,70 & 28 & 47,46 & 29 & 49,14 & 1 & 1,70 & 0 & 0 & 95 & 332 & Setuju \\
\hline 5 & P5 & 1 & 1,70 & 24 & 40,67 & 33 & 55,93 & 1 & 1,70 & 0 & 0 & 95 & 327 & Setuju \\
\hline 6 & P6 & 1 & 1,70 & 26 & 44,06 & 30 & 50,85 & 2 & 3,39 & 0 & 0 & 95 & 329 & Setuju \\
\hline 7 & P7 & 6 & 10,17 & 19 & 32,20 & 28 & 47,47 & 3 & 5,08 & 3 & 5,08 & 95 & 340 & Setuju \\
\hline 8 & P8 & 4 & 6,78 & 17 & 28,82 & 32 & 54,24 & 3 & 5,08 & 3 & 5,08 & 95 & 332 & Setuju \\
\hline 9 & P9 & 2 & 3,39 & 28 & 47,46 & 29 & 49,15 & 0 & 0 & 0 & 0 & 95 & 326 & Setuju \\
\hline 10 & P10 & 1 & 1,70 & 28 & 47,46 & 29 & 49,14 & 1 & 1,70 & 0 & 0 & 95 & 327 & Setuju \\
\hline 11 & P11 & 1 & 1,70 & 24 & 40,67 & 33 & 55,93 & 1 & 1,70 & 0 & 0 & 95 & 327 & Setuju \\
\hline 12 & P12 & 1 & 1,70 & 26 & 44,06 & 30 & 50,85 & 2 & 3,39 & 0 & 0 & 95 & 326 & Setuju \\
\hline 13 & P13 & 6 & 10,17 & 19 & 32,20 & 28 & 47,47 & 3 & 5,08 & 3 & 5,08 & 95 & 331 & Setuju \\
\hline 14 & P14 & 4 & 6,78 & 17 & 28,82 & 32 & 54,24 & 3 & 5,08 & 3 & 5,08 & 95 & 326 & Setuju \\
\hline 15 & P15 & 2 & 3,39 & 28 & 47,46 & 29 & 49,15 & 0 & 0 & 0 & 0 & 95 & 328 & Setuju \\
\hline 16 & P16 & 1 & 1,70 & 28 & 47,46 & 29 & 49,14 & 1 & 1,70 & 0 & 0 & 95 & 326 & Setuju \\
\hline 17 & P17 & 1 & 1,70 & 24 & 40,67 & 33 & 55,93 & 1 & 1,70 & 0 & 0 & 95 & 331 & Setuju \\
\hline 18 & P18 & 1 & 1,70 & 26 & 44,06 & 30 & 50,85 & 2 & 3,39 & 0 & 0 & 95 & 328 & Setuju \\
\hline \multirow{2}{*}{\multicolumn{8}{|c|}{$\begin{array}{c}\text { Total } \\
\text { Rata-rata }\end{array}$}} & & & & & & 5951 & Kuat \\
\hline & & & & & & & & & & & & & 330,6 & Kuat \\
\hline
\end{tabular}

Sumber: data diolah (2016)

\section{Pengawasan (X3)}

Pengawasan pada Dinas Pekerjaan Umum (PU) Kabupaten Batang Hari Jambi termasuk dalam katagori "Kuat" dengan total skor variabel pengawasan (X3) sebesar 2.656 dengan rentang skala 2.584 - 3191, hal ini menunjukkan metode atau cara Pengawasan digunakan, dapat meningkatkan kinerja pegawai pada Dinas Pekerjaan Umum (PU) Kabupaten Batang Hari Jambi dalam melaksanakan tugas seharihari.(tabel 5)

Tabel 5 Tanggapan responden mengenai Pengawasan (X3)

\begin{tabular}{|c|c|c|c|c|c|c|c|c|c|c|c|c|c|c|}
\hline \multirow[t]{2}{*}{ No } & \multirow[t]{2}{*}{ Item } & \multicolumn{2}{|c|}{ SB } & \multicolumn{2}{|r|}{ B } & \multicolumn{2}{|c|}{ CB } & \multicolumn{2}{|c|}{ TB } & \multicolumn{2}{|c|}{ STB } & \multirow[t]{2}{*}{$\mathrm{n}$} & \multirow{2}{*}{$\begin{array}{l}\text { Skor } \\
\text { total }\end{array}$} & \multirow[t]{2}{*}{ Kategori } \\
\hline & & $\mathrm{Fi}$ & $\%$ & $\mathbf{F i}$ & $\%$ & $\mathrm{Fi}$ & $\%$ & $\mathrm{Fi}$ & $\%$ & $\mathrm{Fi}$ & $\%$ & & & \\
\hline 1 & P1 & 21 & 35,59 & 23 & 38,98 & 12 & 20,34 & 2 & 3,39 & 1 & 1,70 & 95 & 325 & Setuju \\
\hline 2 & P2 & 5 & 8,48 & 30 & 50,84 & 21 & 35,59 & 1 & 1,70 & 2 & 3,39 & 95 & 331 & Setuju \\
\hline 3 & P3 & 0 & 0 & 21 & 35,59 & 36 & 61,02 & 2 & 3,39 & 0 & 0 & 95 & 340 & Setuju \\
\hline 4 & P4 & 0 & 0 & 27 & 45,77 & 30 & 50,84 & 2 & 3,39 & 0 & 0 & 95 & 332 & Setuju \\
\hline 5 & P5 & 14 & 23,73 & 24 & 40,67 & 19 & 32,20 & 1 & 1,70 & 1 & 1,70 & 95 & 327 & Setuju \\
\hline 6 & P6 & 0 & 0 & 30 & 50,84 & 27 & 45,76 & 1 & 1,70 & 1 & 1,70 & 95 & 329 & Setuju \\
\hline 7 & P7 & 0 & 0 & 37 & 62,71 & 19 & 32,20 & 2 & 3,39 & 1 & 1,70 & 95 & 340 & Setuju \\
\hline 8 & P8 & 0 & 0 & 30 & 50,84 & 25 & 42,38 & 2 & 3,39 & 2 & 3,39 & 95 & 332 & Setuju \\
\hline & & & & & & tal & & & & & & & 2656 & Kuat \\
\hline
\end{tabular}


Motivasi (Y).

Motivasi pada Dinas Pekerjaan Umum (PU) Kabupaten Batang Hari Jambi termasuk dalam katagori "Kuat" dengan total skor variabel Motivasi (Y) sebesar 3.664 dengan rentang skala 3.230 - 3.989, hal ini menunjukkan metode atau cara motivasi yang digunakan, dapat meningkatkan kinerja pegawai pada Dinas Pekerjaan Umum (PU) Kabupaten Batang Hari Jambi (Tabel 6).

Tabel 6 Tanggapan responden mengenai motivasi (Y)

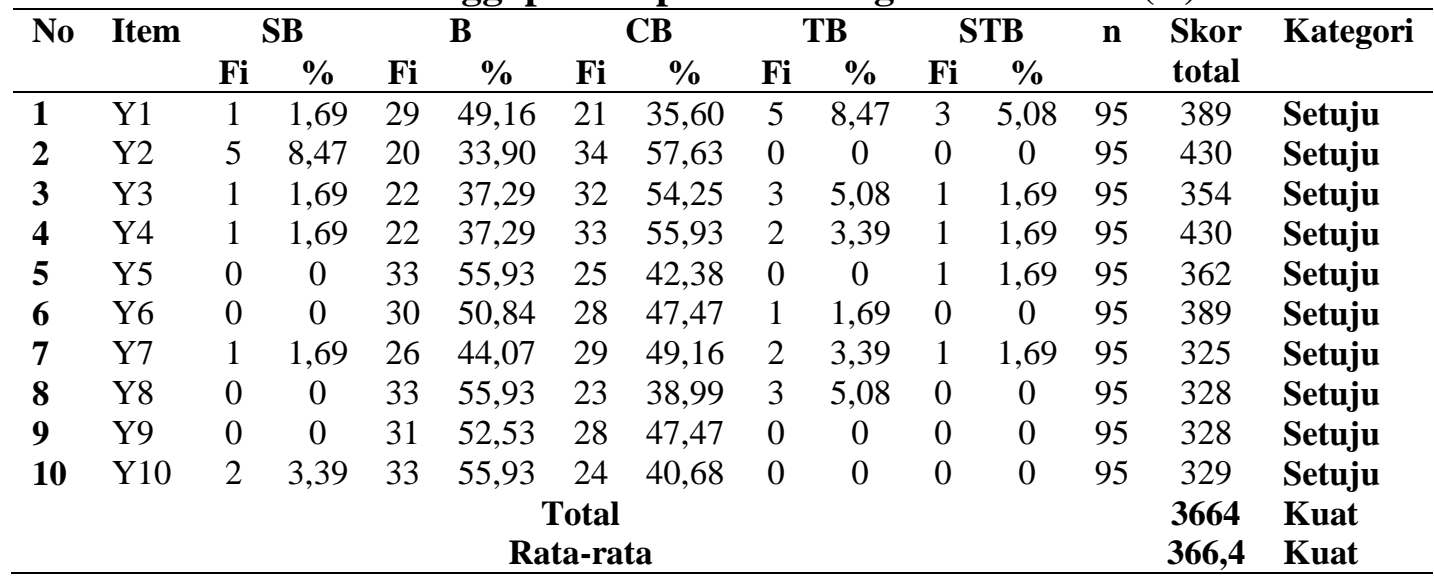

Sumber: data diolah (2016)

\section{Kinerja (Z).}

Kinerja pada Dinas Pekerjaan Umum (PU) Kabupaten Batang Hari Jambi termasuk dalam katagori "Baik" dengan total skor variabel kinerja (Z) sebesar 3.222 dengan rentang skala 3.230 - 3.989, hal ini menunjukkan metode atau cara yang digunakan, dapat meningkatkan kinerja pegawai pada Dinas Pekerjaan Umum (PU) Kabupaten Batang Hari Jambi (Tabel 7).

Tabel 7 Tanggapan responden mengenai kinerja $(Z)$

\begin{tabular}{|c|c|c|c|c|c|c|c|c|c|c|c|c|c|c|}
\hline \multirow[t]{2}{*}{ No } & \multirow[t]{2}{*}{ Item } & \multicolumn{2}{|c|}{ SB } & \multicolumn{2}{|c|}{ B } & \multicolumn{2}{|c|}{ CB } & \multicolumn{2}{|c|}{ TB } & \multicolumn{2}{|c|}{ STB } & \multirow[t]{2}{*}{$\mathbf{n}$} & \multirow{2}{*}{$\begin{array}{l}\text { Skor } \\
\text { total }\end{array}$} & \multirow[t]{2}{*}{ Kategori } \\
\hline & & $\mathbf{F i}$ & $\%$ & $\mathbf{F i}$ & $\%$ & $\mathrm{Fi}$ & $\%$ & $\mathbf{F i}$ & $\%$ & $\mathbf{F i}$ & $\%$ & & & \\
\hline 1 & Z.1 & 3 & 5,09 & 21 & 35,59 & 32 & 54,24 & 3 & 5,08 & 0 & 0 & 95 & 275 & Setuju \\
\hline 2 & Z.2 & 0 & 0 & 27 & 45,77 & 30 & 50,85 & 1 & 1,69 & 1 & 1,69 & 95 & 334 & Setuju \\
\hline 3 & Z.3 & 0 & 0 & 30 & 50,85 & 26 & 44,07 & 2 & 3,39 & 1 & 1,69 & 95 & 315 & Setuju \\
\hline 4 & Z.4 & 0 & 0 & 30 & 50,85 & 25 & 42,37 & 4 & 6,78 & 0 & 0 & 95 & 317 & Setuju \\
\hline 5 & Z.5 & 0 & 0 & 30 & 50,85 & 26 & 44,07 & 1 & 1,69 & 2 & 3,39 & 95 & 337 & Setuju \\
\hline 6 & Z.6 & 0 & 0 & 28 & 47,46 & 28 & 47,46 & 2 & 3,39 & 1 & 1,69 & 95 & 327 & Setuju \\
\hline 7 & Z.7 & 0 & 0 & 29 & 49,16 & 27 & 45,76 & 2 & 3,39 & 1 & 1,69 & 95 & 326 & Setuju \\
\hline 8 & Z.8 & 0 & 0 & 28 & 47,46 & 28 & 47,46 & 1 & 1,69 & 2 & 3,39 & 95 & 327 & Setuju \\
\hline 9 & Z.9 & 0 & 0 & 29 & 49,16 & 27 & 45,76 & 2 & 3,39 & 1 & 1,69 & 95 & 334 & Setuju \\
\hline 10 & Z.19 & 0 & 0 & 29 & 49,16 & 27 & 45,76 & 2 & 3,39 & 1 & 1,69 & 95 & 341 & Setuju \\
\hline & & & & & & ta & & & & & & & 3233 & Kuat \\
\hline & & & & & & 10 & & & & & & & 323,3 & Kuat \\
\hline
\end{tabular}

Sumber: data diolah (2016)

Analisis Jalur Struktur I

Pengaruh Budaya Organisasi (X1) terhadap Motivasi (Y).

Pengaruh langsung Budaya organisasi (X1) terhadap motivasi (Y) 2,25\% dan pengaruh tidak langsung Budaya Organisasi (X1) melalui Gaya Kepemimpinan (X2) terhadap motivasi (Y) sebesar 0,12 \%, dan melalui Pengawasan (X3) sebesar 0,56\% . 
Jadi total pengaruh Budaya organisasi (X1) terhadap motivasi (Y) sebesar 2,69\%. Hal ini berarti bahwa Budaya Organisasi (X1) secara langsung dan tidak langsung berpengaruh positif terhadap motivasi (Y) pegawai Dinas Pekerjaan Umum (PU) Kabupaten Batang Hari Jambi.

Pengaruh Gaya Kepemimpinan (X2) terhadap Motivasi (Y).

Pengaruh langsung gaya kepemimpinan (X2) terhadap motivasi (Y) sebesar sebesar 0,39\% dan pengaruh tidak langsung gaya kepemimpinan (X2) melalui Budaya organisasi (X1) terhadap motivasi (Y) $0,12 \%$, melalui pengawasan (X3) 0,04\%. Jadi total pengaruh gaya kepemimpinan (X2) terhadap motivasi (Y) sebesar 0,199\%.Hal ini berarti bahwa Gaya kepemimpinan (X2) secara langsung dan tidak langsung berpengaruh positif terhadap motivasi (Y) pegawai Dinas pekerjaan Umum (PU) Kabupaten Batang hari Jambi.

Pengaruh Pengawasan (X3) terhadap Motivasi (Y).

pengaruh langsung pengawasan (X3) terhadap motivasi (Y) sebesar 0,15\% dan pengaruh tidak langsung pengawasan (X3) melalui Budaya organisasi (X1) terhadap motivasi (Y) 0,56\%, melalui gaya kepemimpinan (X2) 0,04\%. Jadi total pengaruh pengawasan (X3) terhadap motivasi (Y) sebesar 0,615\%. Hal ini berarti bahwa pengawasan (X3) secara langsung dan tidak langsung berpengaruh positif terhadap motivasi (Y) pegawai Dinas pekerjaan Umum (PU) Kabupaten Batang hari Jambi.

Pengaruh langsung dan tidak langsung Budaya Organisasi (X1) dan Gaya Kepemimpinan (X2) Pengawasan (X3) terhadap Motivasi (Y) (dalam persen).

Dari hasil analisis yang dilakukan, pengaruh langsung dan tidak langsung Budaya Organisasi, Gaya kepemimpinan dan pengawasan secara bersama-sama terhadap motivasi sebesar 3,59\%, angka tersebut menjelaskan bahwa secara langsung Budaya organisasi, gaya kepemimpinan dan pengawasan memberikan sumbangan terhadap motivasi pada pegawai Dinas Pekerjaan Umum (PU) Kabupaten Batang Hari Jambi (Tabel 8).

Tabel 8 Rekapitulasi pengaruh langsung dan tidak langsung budaya organisasi (X1) dan gaya kepemimpinan (X2) dan pengawasan (X3) terhadap Motivasi (Y) (dalam persen).

\begin{tabular}{|c|c|c|c|c|c|c|}
\hline \multirow{2}{*}{ Variabel } & \multirow{2}{*}{ Langsung } & \multicolumn{3}{|c|}{ Tidak langsung } & \multirow{2}{*}{$\begin{array}{c}\text { Sub } \\
\text { Total }\end{array}$} & \multirow[t]{2}{*}{ Total } \\
\hline & & $\mathrm{X} 1$ & $\mathrm{X} 2$ & $\mathrm{X} 3$ & & \\
\hline Budaya Organisasi (X1) & 2,25 & 0,68 & \multirow{3}{*}{0,16} & \multirow{5}{*}{0,60} & 0,68 & 2,93 \\
\hline Gaya kepemimpinan (X2) & 0,39 & & & & 0,16 & 0,55 \\
\hline \multirow[t]{3}{*}{ Pengawasan (X3) } & 0,15 & & & & 0,60 & 0,75 \\
\hline & \multirow{2}{*}{\multicolumn{3}{|c|}{$\begin{array}{c}\text { Pengaruh X1, X2 dan X3 } \\
\text { Pengaruh Variabel Lain }\end{array}$}} & & & 4,23 \\
\hline & & & & & & 95.77 \\
\hline
\end{tabular}

Sumber: Data diolah (2016)

Analisis Jalur Struktur II

Pengaruh Budaya Organisasi (X1) terhadap Kinerja (Z).

Pengaruh langsung budaya organisasi terhadap kinerja adalah sebesar $0,70 \%$ dan pengaruh tidak langsung melalui variabel X2 sebesar $0,14 \%$, melalui varabel X3 sebesar $0,56 \%$. Hal ini menunjukkan bahwa budaya organisasi secara langsung berpengaruh positif terhadap kinerja.

Pengaruh Gaya Kepemimpinan (X2) terhadap Kinerja (Z).

pengaruh langsung variabel $\mathrm{X} 2$ terhadap $\mathrm{Z}$ adalah sebesar $1,76 \%$ dan pengaruh tidak langsung variabel X2 terhadap Z melalui X1 adalah sebesar 0,14\%, melalui X3 
sebesar0,14\%. Jadi pengaruh total sebesar $2.04 \%$. Artinya kinerja pegawai dipengaruhi oleh gaya kepemimpinan

Pengaruh Pengawasan (X3) terhadap Kinerja (Z).

Pengaruh langsung variabel $\mathrm{X} 3$ terhadap $\mathrm{Z}$ adalah sebesar $0,56 \%$ dan pengaruh tidak langsung variabel X3 terhadap Z melalui X1 adalah sebesar 0,56\%, melalui X2 sebesar0,14\%. Jadi pengaruh total sebesar 5,60 \%. Artinya kinerja pegawai dipengaruhi oleh pengawasan

Pengaruh langsung dan tidak langsung Budaya Organisasi (X1) gaya kepemimpinan (X2) dan Pengawasan (X3) terhadap kinerja (Z) pegawai.

Dari hasil analisis yang dilakukan terlihat budaya organisasi, gaya kepemimpinan dan pengawasan memiliki kontribusi sumbangan sebesar 9,04\% terhadap kinerja dan sisanya 90,96\% dipengaruhi oleh faktor lain diluar variabel yang diteliti (Tabel 8).

Tabel 9 Rekapitulasi pengaruh langsung dan tidak langsung budaya organisasi (X1) gaya kepemimpinan (X2) dan pengawasan (X3) terhadap kinerja $(\mathrm{Z})$ pegawai.

\begin{tabular}{lcccccc}
\hline \multicolumn{1}{c}{ Variabel } & Langsung & \multicolumn{3}{c}{ Tidak langsung } & Sub & Total \\
& \multicolumn{2}{c}{ X1 } & X2 & X3 & Total & \\
\hline Budaya Organisasi (X1) & 0,70 & 0,70 & & & 0,70 & 1,40 \\
Gaya kepemimpinan (X2) & 1,76 & & 0,28 & & 0,28 & 2,04 \\
Pengawasan (X3) & 4,90 & & 0,70 & 0,70 & 5,60 \\
& Pengaruh X1, X2 dan X3 & & & 9,04 \\
& Pengaruh Variabel Lain & & 90.96 \\
\hline
\end{tabular}

Sumber: data diolah (2016)

Pengaruh budaya organisasi (X1) dan gaya kepemimpinan (X2)dan pengawasan (X3) secara bersama-sama terhadap Kinerja (Z).

Pengaruh langsung dan tidak langsung Budaya organisasi, gaya kepemimpinan dan pengawasan secara bersama-sama terhadap kinerja adalah sebesar 52,3\%, angka tersebut menjelaskan bahwa secara langsung budaya organisasi, gaya kepemimpinan dan pengawasan memberikan sumbangan terhadap kinerja pada pegawai Dinas pekerjaan Umum (PU) kabupaten Batanghari Jambi.

\section{Analisis Jalur Struktur III}

Pengaruh budaya organisasi (X1) melalui Motivasi (Y) terhadap Kinerja (Z).

Budaya organisasi melalui motivasi terhadap kinerja pengaruhnya sebesar $0.018 \%$, dan pengaruh budaya organisasi terhadap kinerja melalui gaya kepemimpinan, pengawasan dan motivasi adalah sebesar 0,000058\% dan total pengaruhnya adalah sebesar $0,018 \%$, dimana angka tersebut menjelaskan bahwa budaya organisasi melalui motivasi, gaya kepemimpinan dan pengawasan memberikan sumbangan terhadap kinerja pegawai dinas pekerjaan Umum (PU) Kabupaten batang harii Jambi.

Pengaruh gaya kepemimpinan (X2) melalui Motivasi (Y) terhadap Kinerja (Z).

Gaya kepemimpinan melalui motivasi terhadap kinerja pengaruhnya sebesar $0,123 \%$, dan pengaruh gaya kepemimpinan melalui Budaya organisasi, pengawasan dan motivasi terhadap kinerja adalah sebesar 0,00036\% dan total pengaruhnya adalah $0,123 \%$. Gaya kepemimpinan melalui motivasi memberikan sumbangan terhadap kinerja pegawai Dinas Pekerjaan Umum (PU) Kabupaten Batang Hari Jambi. 
Pengaruh Pengawasan (X3) melalui Motivasi (Y) terhadap Kinerja (Z).

Pengawasan melalui motivasi terhadap kinerja pengaruhnya sebesar 0,040\%, dan pengaruh pengawasan melalui Budaya organisasi, gaya kepemimpinan dan motivasi terhadap kinerja adalah sebesar $0,00086 \%$ dan total pengaruhnya adalah $0,040 \%$. pengawasan melalui motivasi memberikan sumbangan terhadap kinerja pegawai Dinas Pekerjaan Umum (PU) Kabupaten Batang Hari Jambi.

Pengaruh Budaya Organisasi (X1) dan Gaya kepemimpinan (X2) dan Pengawasan (X3) secara bersama-sama terhadap Kinerja (Z) melalui Motivasi (Y).

Budaya organisasi, gaya kepemimpinan, dan pengawasan secara bersama-sama melalui motivasi terhadap kinerja adalah sebesar 0,34\%, pengaruh tidak langsung adalah sebesar $0,0001 \%$ dan total pengaruh adalah $0,34 \%$. Dengan demikian dari secara bersama-sama variabel Budaya organisasi, gaya kepemimpinan, pengawasanmelalui motivasi memberikan sumbangan terhadap kinerja para pegawai dinas Pekerjaan Umum (PU) Kabupaten Batang Hari Jambi.

Analisis Jalur Struktur IV

Pengaruh langsung Motivasi (Y) terhadap Kinerja (Z).

Motivasi memiliki pengaruh yang positif sebesar 17,8\% terhadap kinerja pegawai Dinas Pekerjaan Umum Kabupaten Batang Hari Jambi dan 82,2\% dipengaruhi oleh faktor lain diluar variabel motivasi.

Tabel 10 Rekapituasi pengaruh langsung Motivasi terhadap Kinerja

\begin{tabular}{cccc}
\hline Variabel & Langsung $(\mathbf{Z})$ & Sub Total & Total \\
\hline Motivasi (Y) & 17,8 & 17,8 & 17,8 \\
& Pengaruh Y terhadap Z & & 17,8 \\
& Pengaruh variabel lain & & 82,2
\end{tabular}

Sumber : data diolah (2016)

\section{Koefisien Determinasi Struktur I}

Angka $R$ Square sebesar 0,026, angka ini menunjukkan bahwa kontribusi sumbangan variabel independen budaya organisasi (X1), gaya kepemimpinan (X2) dan pengawasan (X3) terhadap variabel motivasi (Y) adalah sebesar 2,6\% tersebut berarti budaya organisasi, gaya kepemimpinan dan pengawasan secara bersama-sama dapat menjelaskan terhadap motivasi, sedangkan 97,4,7\% dipengaruhi atau dijelaskan oleh variabel lain yang tidak dimasukkan dalam model penelitian ini.

\section{Koefisien Determinasi Struktur II}

Angka $R$ Square sebesar 0,024, angka ini menunjukkan bahwa kontribusi sumbangan variabel independen budaya organisasi (X1), gaya kepemimpinan (X2) dan pengawasan (X3) terhadap variabel kinerja (Z) adalah sebesar 2,4\% tersebut berarti budaya organisasi, gaya kepemimpinan dan pengawasan secara bersama-sama dapat menjelaskan terhadap kinerja, sedangkan 97,6\% dipengaruhi atau dijelaskan oleh variabel lain yang tidak dimasukkan dalam model penelitian ini.

\section{Koefisien Determinasi Struktur III}

Angka $R$ Square sebesar 0,022, angka ini menunjukkan bahwa kontribusi sumbangan variabel motivas (Y) terhadap variabel kinerja (Z) adalah sebesar 2,2\% tersebut berarti motivasi secara bersama-sama dapat menjelaskan tentang kinerja pegawai, sedangkan 97,8\% dipengaruhi atau dijelaskan oleh variabel lain yang tidak dimasukkan dalam model penelitian ini 


\section{Pembahasan}

Budaya organisasi, gaya kepemimpinan, pengawasan pegawai dinas Pekerjaan Umum (PU) Kabupaten Batang Hari Jambi berada pada posisi Kuat baik dengan total skor masing-masing 3.841, 6.533 dan 2.917, sedangkan motivasi mendapatkan skor 3.776 dalam katagori Kuat dan kinerja pegawai Dinas Pekerjaan Umum (PU) Kabupaten Batang Hari Jambi mendapatkan skor 3.780 yang masuk dalam katagori Kuat (Tabel 11).

Tabel 11 Hasil analisis Deskriptif per Variabel

\begin{tabular}{lllrl}
\hline No & Variabel & Total Skor & Rentang skala & Hasil Hipotesis \\
\hline 1 & Budaya organisasi & 3.841 & $3.230-3.989$ & Kuat \\
2 & Gaya kepemimpinan & 6.533 & $5.814-7.181$ & Kuat \\
3 & Pengawasan & 2.917 & $2.584-3.191$ & Kuat \\
4 & Motivasi & 3.776 & $3.230-3.989$ & Kuat \\
5 & Kinerja & 3.780 & $3.230-3.989$ & Kuat \\
\hline
\end{tabular}

Sumber: Data primer yang telah diolah 2016

Tabel 12 Uji Parsial antara budaya organisasi, gaya kepemimpinan dan pengawasan terhadap motivasi

Coefficients $^{\mathrm{a}}$

\begin{tabular}{|c|c|c|c|c|c|c|c|c|}
\hline \multirow[b]{2}{*}{ Model } & \multicolumn{2}{|c|}{$\begin{array}{l}\text { Unstandardized } \\
\text { Coefficients }\end{array}$} & \multicolumn{3}{|c|}{$\begin{array}{l}\text { Standardized } \\
\text { Coefficients }\end{array}$} & \multirow[b]{2}{*}{ Sig. } & \multirow[b]{2}{*}{$\mathrm{F}$} & \multirow[b]{2}{*}{ Sig } \\
\hline & B & Std. Error & Beta & & $\mathrm{t}$ & & & \\
\hline 1 (Constant) & 18,17 & 2,259 & & & 8,044 &, 000 & 7,208 & .000 \\
\hline & 3 & & & & & & & \\
\hline budaya & ,003 & , 083 & & ,004 &, 041 & 967 & & \\
\hline Gaya & ,093 & ,043 & & ,224 & 2,167 & ,033 & & \\
\hline pengawasan & ,193 & ,062 & & ,310 & 3,110 & ,002 & & \\
\hline
\end{tabular}

a. Dependent Variable: motivasi

b. Predictors: (Constant), budaya organisasi, gaya kepemimpinan dan pengawasan

Tabel 12 menunjukkan bahwa budaya organisasi, gaya kepemimpinan dan pengawasan mempunyai pengaruh yang positif dan signifikan terhadap motivasi pegawai Dinas Pekerjaan Umum Kabupaten Batang Hari Jambi.

Hasil penelitian didapatkan $t$ hitung 2.167 sedangkan $t$ tabel sebesar 1,66105 (t hitung $>\mathrm{t}$ tabel) dengan signifikasi sebesar 0,33. Kriteria kepuasan jika Sig. penelitian < 0,05 maka H0 ditolak dan HI diterima artinya signifikan, tetapi jika Sig. penelitian > 0,05 maka $\mathrm{H0}$ diterima dan $\mathrm{HI}$ ditolak yang berarti tidak signifikan. Karena 0,033<0,05 maka H0 ditolak dan HI diterima (sidnifikan).

Tabel 13 menunjukkan bahwa budaya organisasi, gaya kepemimpinan dan pengawasan mempunyai pengaruh yang positif dan signifikan terhadap kinerja pegawai Dinas Pekerjaan Umum Kabupaten Batang Hari Jambi. 
Tabel 13 Uji Parsial antara budaya organisas, gaya kepemimpinan dan pengawasan terhadap kinerja

Coefficients $^{\mathrm{a}}$

\begin{tabular}{|c|c|c|c|c|c|c|c|}
\hline \multirow[b]{2}{*}{ Model } & \multicolumn{2}{|c|}{$\begin{array}{l}\text { Unstandardized } \\
\text { Coefficients }\end{array}$} & \multirow{2}{*}{$\begin{array}{l}\text { Standardized } \\
\text { Coefficients } \\
\text { Beta }\end{array}$} & \multirow[b]{2}{*}{$\mathrm{t}$} & \multirow[b]{2}{*}{ Sig. } & \multirow[b]{2}{*}{$\mathrm{F}$} & \multirow[b]{2}{*}{ Sig } \\
\hline & B & $\begin{array}{l}\text { Std. } \\
\text { Error }\end{array}$ & & & & & \\
\hline 1 (Constant) & 11,992 & 2,842 & & 4,220 &, 000 & 9,669 & .000 \\
\hline Budaya &, 181 &, 104 & , 166 & 1,736 & ,086 & & \\
\hline Gaya & ,065 &, 054 &, 120 & 1,193 & ,236 & & \\
\hline pengawasan & ,303 & ,078 & ,376 & 3,895 & ,000 & & \\
\hline
\end{tabular}

a. Predictors: (Constant), budaya organisasi, gaya kepemimpinan, dan pengawasan

b. Dependent Variable: KINERJA

Dari hasil penelitian didapatkan variabel X1 t hitungnya 1.736 sedangkan $\mathrm{t}$ tabel 1.66105, (t hitung > t tabel) dengan nilai Sig 0,086. menunjukkan bahwa secara parsial antra gaya kepemimpinan (X2) dengan kinerja $(\mathrm{Z})$ bahwa nilai t hitung variabel X1 adalah 1.193 sedangkan t tabel 1.66105 ( $\mathrm{t}$ hitung $<\mathrm{t}$ tabel) dengan nilai Sig. 0,236. Kriteria keputusan jika Sig penelitian $<0,05$ maka H0 ditolak dan Hi diterima artinya signifikan, tetapi jika Sig penelitian >0,05 maka H0 diterima dan Hi ditolak yang berarti tidak signifikan. Karena 0,236 > 0,05 maka H0 diterima Hi ditolak (tidak signifikan)

Tabel 13 menunjukkan bahwa secara parsial pengawasan (X3) dengan kinerja (Z) bahwa nilai t hitung variabel (X1) adalah 3.895 sedangkan $t$ tabel 1.66105 , $(\mathrm{t}$ hitung > t tabel) dengan nilai Sig 0,000. Kriteria keputusan jika Sig, penelitian $<0,05$ maka H0 ditolak dan Hi diterima artinya signifikan, tetapi jika Sig penelitian $>0,05$ maka H0 diterima artinya signifikan, tetapi jika Sig penelitian $>0,05$ maka H0 diterima dan Hi ditolak yang berarti tidak signifikan. Karena 0,000 $<0,05$ maka H0 ditolak Hi diterima (signifikan).

Secara simultan variabel budaya organisasi (X1), gaya kepemimpinan (X2) dan pengawasan (X3) dengan variabel motivasi (Y) menunjukkan bahwa F hitung 9.669 dengan taraf signifikansi 0,000

\begin{tabular}{|c|c|c|c|c|c|c|c|}
\hline \multirow[t]{2}{*}{ Model } & \multicolumn{2}{|c|}{$\begin{array}{l}\text { Unstandardized } \\
\text { Coefficients }\end{array}$} & \multirow{2}{*}{$\begin{array}{c}\text { Standardized } \\
\text { Coefficients } \\
\text { Beta }\end{array}$} & \multirow[t]{2}{*}{$\mathrm{t}$} & \multirow[t]{2}{*}{ Sig } & \multirow[t]{2}{*}{$\mathrm{F}$} & \multirow[t]{2}{*}{ Sig } \\
\hline & B & Std.Error & & & & & \\
\hline 1.(Constant) & 10,332 & 3,090 & & 3,344 &, 001 & 20,138 & .000 \\
\hline $\mathrm{Y}$ &, 548 &, 122 & ,422 & 4,488 & ,000 & & \\
\hline
\end{tabular}

a. Dependent Variable: KINERJA

b. Predictors: (Constant), MOTIVASI

Nilai t hitung variabel motivasi (Y) adalah 4.488 dengan taraf signifikansi 0,000. Kriteria keputusan jika Sig penelitian $<0,05$ maka Ho ditolak dan Hi diterima artinya signifikan, tetapi jika Sig penelitian $>0,05$ maka Ho diterima dan Hi ditolak yang berarti tidak Signifikan. Karena $0,000<0,05$ maka Ho ditolak Hi diterima (signifikan).

Pengaruh Budaya Organisasi, Gaya Kepemimpinan dan Pengawas terhadap Motivasi Serta Dampaknya terhadap Kinerja Pegawai Dinas Pekerjaan Umum (PU) Kabupaten Batang Hari Jambi 


\section{SIMPULAN}

1. Hasil analisis deskriptif untuk variabel budaya organisas, gaya kepemimpinan, pengawasan terhadap motivasi serta dampaknya terhadap kinerja pegawai pada Dinas Pekerjaan Umum Kabupaten Batanghari Jambi adalah: variabel budaya organisasi (X1) total skor 3.841 dengan rentang skala 3.230 - 3.989 hasil hipotesis kuat, gaya kepemimpinan (X2) total skor 6.533 dengan rentang skala 5.814 7,181 hasil hipotesis kuat, pegawasan (X3) total skor 2.917 dengan rentang skala 2.584 - 3.191 hasil hipotesis kuat, motivasi (Y) total skor 3.776 dengan rentang skala 3.230 - 3.989 hasil hipotesis kuat, serta kinerja $(Z)$ total skor 3.780 dengan rentang skala 3.230 - 3.989 hasil hipotesis kuat.

2. Dari hasil pengujian hipotesis secara simultan antara variabel budaya organisasi (X1), gaya kepemimpinan (X2), pengawasan (X3) dengan variabel motivasi (Y) menunjukkan bahwa F hitung 7.208 dengan taraf signifikansi 0,000

3. Dari hasil pengujian hipotesis secara simultan antara variabel budaya organisasi (X1), gaya kepemimpinan (X2), pengawasan (X3), dengan variabel motivasi (Y) menunjukkan bahwa F hitung 9.669 dengan taraf signifikan 0.000. dari tabel diatas menunjukkan bahwa nilai t hitung variabel motivasi $(\mathrm{Y})$ adalah 4.488 dengan taraf signifikan 0.000. karena 0,000 $<0.05$ maka H0 ditolak Ho diterima ( signifikan). Hasil menunjukkan bahwa secara parsial motivasi (Y) berpengaruh terhadap kinerja (Z) pada Dinas Pekerjaan Umum Kabupaten Batanghari Jambi.

4. Budaya organisasi (X1), gaya kepemimpinan (X2), pengawasan (X3) melalui motivasi (Y) terhadap Kinerja (Z) pada Dinas Pekerjaan Umum Kabupaten Batanghari Jambi. Secara simultan antara variabel X1, X2, dan X3, melalui Y dengan variabel kinerja $(Z)$ menunjukkan bahwa $F$ hitung 20.138 dengan taraf signifikansi 0.000 .

\section{DAFTAR PUSTAKA}

Arikunto, Suharsimi. 2007. Prosedur Penelitian Suatu, pendekatan praktek. Edisi revisi, Jakarta : PT. Rineka Cipta.

Brantas (2009). Dasar-dasar Manajemen. Alfabeta, Bandung.

Faustino Cardoso. 2003. Manajemen Sumber Daya manusia. Andi Offset. Jakarta

Linda, Rahma. 2016. Tesis. Pengaruh Pelatihan dan Penempatan Terhadap Motivasi Serta Dampaknya Terhadap Kinerja Pegawai Perusahaan Air Minum (PDAM)

Tirta Batang Hari. Universitas Batang Hari. Jambi

Manullang dan Marihot. 2002. Manajemen Personalia. Yogyakarta: Badan Percetakan UGM

Mangkunegara, A.A. Prabu. (2013). Manajemen Sumber Daya Manusia Perusahaan, Remaja Rosdakarya. Bandung

Syekh, Sayid (2011), Pengantar Statistik Ekonomi dan Sosial. Gaung Persada Pers, Jakarta

Siregar. 2009. Pengaruh Gaya Kepemimpinan dan Kemampuan Berkomunikasi Kepala Bidang Terhadap Kinerja Pegawai Pelayanan Keperawatan Jiwa Di Rumah Sakit Jiwa Daerah Provinsi Sumatra Utara.

Sardiman, 2001, Ekonomi Sumber Daya Manusia , PAU UI, Jakarta.

Sunyoto, Danag. 2013. Manajemen Sumber Daya Manusia. Cetakan Kedua. Center For Academic Publising Service (CAPS). Yogyakarta.

Pengaruh Budaya Organisasi, Gaya Kepemimpinan dan Pengawas terhadap Motivasi Serta Dampaknya terhadap Kinerja Pegawai Dinas Pekerjaan Umum (PU) Kabupaten Batang Hari Jambi 
Tika, Pabundu. 2006. Budaya Organisasi dan Peningkatan Kinerja Perusahaan. Jakarta : Bumi Aksara.

Wahyudi, 2012. Manajemen Konflik Dalam Organisasi. Raja Grafindo Persada. Jakarta 